\title{
Proposta de gestão integrada das águas urbanas como estratégia de promoção da segurança hídrica: o caso de Fortaleza
}

\author{
Proposal of integrated urban waters management as a \\ strategy to promote water security: the Fortaleza case
}

\section{Samiria Maria Oliveira Silva'* ${ }^{1 *}$, Francisco de Assis Souza Filho' ${ }^{\oplus}$, Daniel Antônio Camelo Cid ${ }^{\circledR}$, Sandra Helena Silva de Aquino' ${ }^{\oplus}$, Louise Caroline Peixoto Xavier ${ }^{1} \odot$}

口-

\begin{abstract}
RESUMO
O estudo propõe a utilização de modelos de gestão integrada de águas urbanas como estratégia para a promoção da segurança hídrica e de preparação às secas. Ele foi construído em duas etapas: avaliação da vulnerabilidade do sistema hídrico; e proposição do modelo de gestão integrada de águas urbanas. Na primeira etapa, utilizou-se um modelo de rede de fluxo para a simulação do sistema hídrico. Na segunda etapa, aplicouse o método indutivo após a realização de pesquisa exploratória. A avaliação das vulnerabilidades hídricas revelou déficit de atendimento de Fortaleza em 2,56\% do período simulado e o esvaziamento completo do reservatório Castanhão em 6,52\% dos meses. O modelo de gestão integrada de águas urbanas é pautado na gestão da oferta e da demanda hídricas. No primeiro caso, propõe-se que o sistema de abastecimento de Fortaleza seja constituído por fontes hídricas convencionais (águas superficiais) e por mananciais alternativos (águas subterrâneas, águas pluviais, dessalinização de água do mar). Para a gestão da demanda, aponta-se a utilização de aparelhos sanitários economizadores e de mecanismos financeiros. Esse modelo apresenta uma matriz de fontes de abastecimento mais robusta, o que possibilita o aumento da segurança hídrica de centros urbanos.
\end{abstract}

Palavras-chave: seca; urbano; gestão.

\begin{abstract}
The study proposes the use of integrated urban water-management models as a strategy to promote water security and drought preparedness. It was developed in two stages: assessment of water system's vulnerability; proposition of the integrated urban water management model. In the first step, a flow network model was used to simulate the water system. In the second stage, the inductive method was applied after conducting an exploratory research. The assessment of the water vulnerabilities revealed a deficit in Fortaleza's water supply in $2.56 \%$ of the simulated period and the complete emptying of Castanhão's reservoir in $6.52 \%$ of the months. The integrated urban water management model is based on the management of water supply and water demand. In the first case, it is proposed that Fortaleza's supply system be constituted by conventional water sources (surface waters) and by alternative sources (groundwater, rainwater, desalination of sea water). For the management of demand, it is pointed out the use of water saving plumbing fixtures and financial mechanisms. This model presents a more robust matrix of water supply sources, which increases the water security of urban centers.
\end{abstract}

Keywords: drought; urban; management.

\section{INTRODUÇÃO}

A água é um elemento vital para a sustentabilidade dos centros urbanos. Quando gerenciada de forma deficiente, são comprometidos a saúde e o bem-estar da população, a economia e o meio ambiente.

As discussões sobre o acesso à água, em termos quantitativos e qualitativos, despontam como uma das urgências da contemporaneidade. É a denominada segurança hídrica, conceito que passou a ser difundido a partir da Declaração Ministerial do $2^{\circ}$ Fórum Mundial da Água, ocorrido na cidade de Haia, Holanda, em 2000, como a:

Capacidade de uma população para garantir o acesso sustentável a quantidades adequadas de água, com qualidade aceitável para a subsistência, o bem-estar humano e o desenvolvimento socioeconômico, assegurando a proteção dos recursos hídricos contra a poluição e os desastres relacionados com a água, bem como a 
preservação dos ecossistemas em um clima de paz e estabilidade política (UN-WATER, 2013).

A segurança hídrica associa-se às categorias segurança alimentar $\mathrm{e}$ segurança ambiental, evidenciando a necessidade de uma gestão pautada na incerteza, na adaptação e nos riscos de falha do sistema hídrico. Um desses riscos é a seca, fenômeno recorrente do clima em algumas regiões. Os impactos das secas ocorrem em diferentes setores socioeconômicos e requerem medidas no âmbito de diferentes políticas setoriais.

Especificamente, planejar repostas às secas em centros urbanos requer o desenvolvimento de uma abordagem holística e proativa que propicie a visão e a análise dos diversos riscos, sendo capaz de propor ações sistemáticas e antecipadas. Assim, novas políticas, regulamentos, modelos, técnicas e investimentos serão sempre necessários para gerir impactos decorrentes do crescimento populacional, da infraestrutura que se deteriora, do crescimento urbano, das mudanças climáticas e de muitas outras pressões atuais e futuras sobre o sistema hídrico (PHILIP \& SALIAN, 2011).

Nesse sentido, este estudo propôs a utilização de modelos de gestão integrada de águas urbanas como estratégia para a promoção da segurança hídrica e de preparação às secas. Para isso, as análises foram separadas em duas etapas:

- avaliação da vulnerabilidade do sistema hídrico;

- proposição do modelo de gestão integrada de águas urbanas.

A primeira etapa visa identificar as falhas de abastecimento do sistema hídrico. A segunda expõe um modelo pautado tanto na gestão da oferta quanto na gestão da demanda hídricas, proporcionando a gestão das águas sem perder o vínculo com os diversos componentes do sistema hídrico urbano.

A área de análise é a cidade de Fortaleza, capital do Estado do Ceará, Brasil, a qual passou por um período de quatro anos de seca (2012-2015) e apresenta problemas de drenagem urbana, inundações e poluição de seus corpos hídricos, configurando-se como um laboratório para o aprimoramento e o desenvolvimento de métodos e práticas de gerenciamento dos recursos hídricos.

\section{GESTÃO INTEGRADA DE ÁGUAS URBANAS}

No modelo convencional de gerenciamento de águas urbanas, o abastecimento de água, o esgotamento sanitário e a drenagem urbana são, fisicamente, três sistemas separados. Papéis e responsabilidades sobre a gestão da água nas cidades estão espalhados por diferentes níveis de governo e uma ampla gama de partes interessadas, como autoridades públicas, fornecedores, reguladores e organizações de bacias hidrográficas (OECD, 2016).

Os elementos do ciclo hidrológico urbano, contudo, estão indissociavelmente ligados, isto é, a boa ou má gestão de um elemento pode influenciar no sucesso da gestão de outro, o que resulta em impactos indesejados em outras partes do ciclo. Além disso, as variáveis do ciclo hidrológico urbano (volume infiltrado, escoado e precipitado) estão em constante mudança. Alterações da população, desenvolvimento urbano, riqueza, política, tecnologia, clima, entre outros fatores, geram contínuos impactos sobre os sistemas hídricos e os grupos de interesse que, de diversas maneiras, dependem deles (PHILIP \& SALIAN, 2011).

Alcançar uma perspectiva holística, capaz de levar em consideração essas relações, é um desafio para o modelo de gestão integrada de águas urbanas. Na integração preconizada para essa gestão, devem-se considerar, de modo inter-relacionado:

- os componentes do ciclo hidrológico;

- os aspectos quantitativos e qualitativos dos recursos hídricos;

- $\quad$ as três esferas de poder (Executivo, Legislativo e Judiciário);

- as políticas públicas;

- os setores econômicos e privados.

Em conjunto com todos esses elementos, deve haver a integração dos aspectos social, econômico e de proteção ao meio ambiente no âmbito da visão de desenvolvimento.

Nessa nova abordagem, a integração física e institucional dos diversos componentes do sistema hídrico está prevista no projeto. Vínculos são estabelecidos entre o abastecimento de água, o esgotamento sanitário e o manejo das águas pluviais, assim como outros elementos da urbanização, por meio da gestão altamente coordenada (PHILIP et al., 2011).

\section{LOCAL DE APLICAÇÃO}

A área urbana considerada neste estudo é a cidade de Fortaleza, localizada no litoral atlântico e no semiárido nordestino do Brasil. Trata-se de um município totalmente urbano que alcançou 2,5 milhões de habitantes em 2010, segundo o Instituto Brasileiro de Geografia e Estatística (IBGE) (2012), possui produto interno bruto (PIB) per capita de $\mathrm{R} \$ 16.963,00$ calculado para o ano de 2011 (IPECE, 2014) e precipitação média anual de $1.397 \mathrm{~mm}$, com pronunciada variabilidade interanual, sazonal e decadal. Em termos de planejamento, Fortaleza está inserida na Região Metropolitana de Fortaleza (RMF).

O suprimento superficial para o abastecimento de Fortaleza é consolidado por oito reservatórios: cinco deles situados na RMF (Gavião, Pacoti, Riachão, Pacajus e Aracoiaba) e três na bacia do Jaguaribe (Orós, Castanhão e Banabuiú), formando o Jaguaribe-Metropolitano, principal sistema de reservatório do Estado do Ceará (Figura 1).

A porção metropolitana, sistema local, tem capacidade de acumulação de $871 \mathrm{hm}^{3}$, e a porção do Jaguaribe, de $10.241 \mathrm{hm}^{3}$, dividida entre Orós $\left(1.940 \mathrm{hm}^{3}\right)$, Banabuiú $\left(1.601 \mathrm{hm}^{3}\right)$ e Castanhão $\left(6.700 \mathrm{hm}^{3}\right)$. Descontado o volume de espera da cheia do Castanhão, o volume útil desse sistema para os usos urbanos, de irrigação e industrial é de 
$8.002 \mathrm{hm}^{3}$. As duas regiões hidrográficas, Jaguaribe e Metropolitana, são interligadas por duas obras de transferência hídrica: o Canal do Trabalhador e o Eixão das Águas.

Em Fortaleza, a captação de água bruta é realizada no açude Gavião por meio de torre de tomada, galeria e canal - e transferida para as Estações de Tratamento de Água (ETAs) Oeste e Gavião. Saindo das ETAs, a água é transportada e distribuída por meio de estações elevatórias, centros de reservação (sendo o principal deles o reservatório Ancuri) e rede de distribuição.

\section{METODOLOGIA}

Para desenvolver o estudo, inicialmente, verificaram-se as vulnerabilidades hídricas quantitativas do sistema e, em seguida, foi proposto o modelo de gestão integrada de águas urbanas. Essas duas etapas estão associadas conforme a Figura 2.

\section{Análise das vulnerabilidades hídricas}

As vulnerabilidades hídricas do sistema foram analisadas pelos critérios de frequência de falha das demandas, curva de permanência e

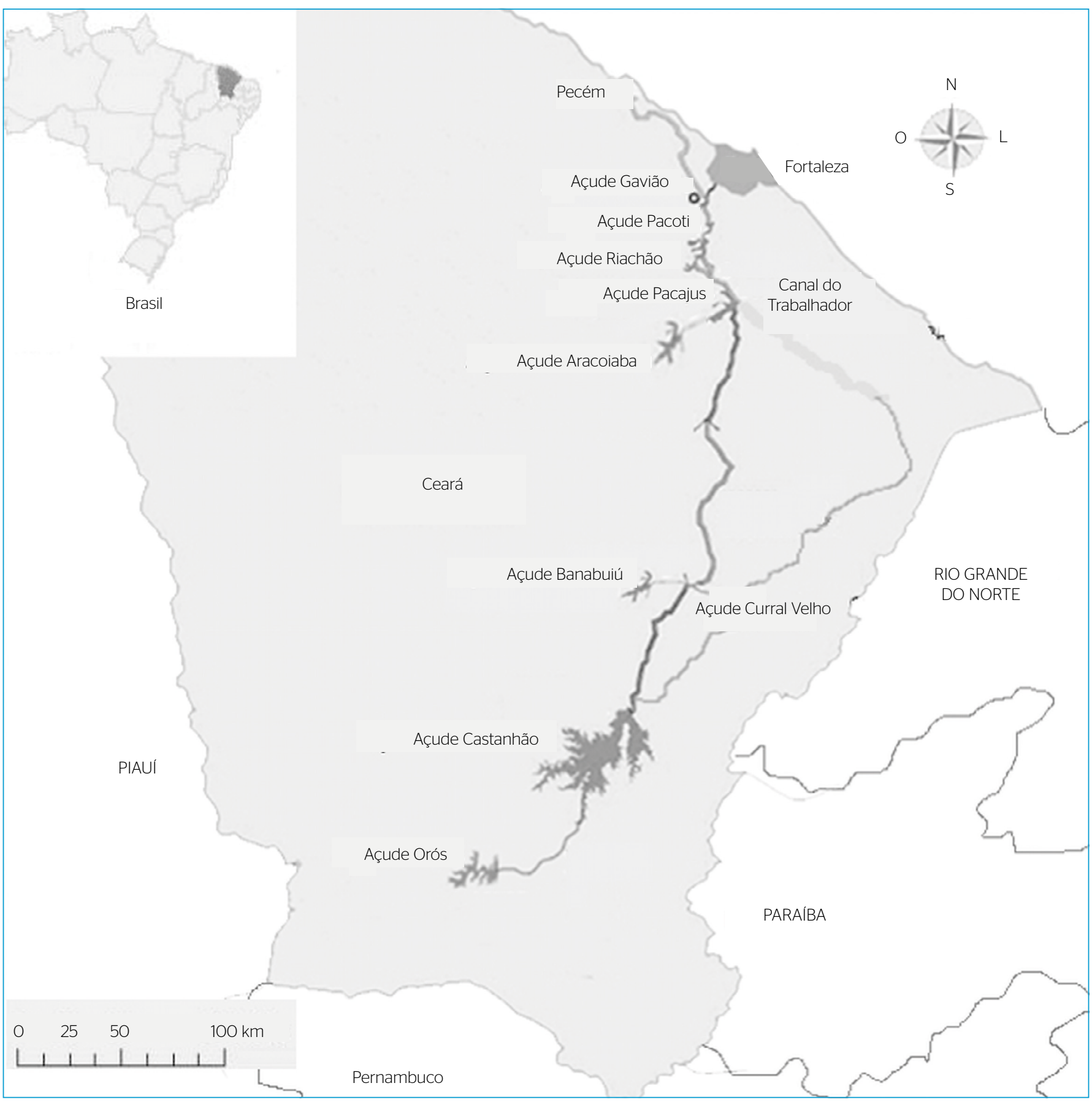

Figura 1 - Sistema Jaguaribe-Metropolitano. 
acumulação dos reservatórios. Para isso, realizaram-se a operação e a simulação do sistema Jaguaribe-Metropolitano por meio do modelo AcquaNet, desenvolvido pelo Laboratório de Sistemas de Suporte a Decisões em Engenharia Ambiental e de Recursos Hídricos da Escola Politécnica da Universidade de São Paulo (USP) (LABSID, 2002).

O AcquaNet permite a análise integrada do balanço hídrico mensal considerando todos os reservatórios, canais, adutoras e demandas hídricas das regiões do Jaguaribe e Metropolitana.

Para tanto, consideram-se na operação real do sistema de abastecimento de Fortaleza dois tipos de restrição física:

- capacidade do transporte de água nos canais;

- cota do reservatório necessária para o bombeamento das águas estocadas (cota mínima).

Entre essas restrições, destacam-se: a capacidade máxima de transporte do Eixão das Águas e do Canal do Trabalhador $(9$ e 3 m³ $/$, respectivamente); o volume mínimo operacional do reservatório PacotiRiachão (36,16 m, correspondendo a aproximadamente $25 \%$ do seu volume total de acumulação); e o volume mínimo operacional do Castanhão $\left(220 \mathrm{hm}^{3}\right)$.

\section{Operação e simulação do sistema hídrico}

A operação da rede de abastecimento de água bruta e a alocação de água foram realizadas pela aplicação de um sistema de prioridades e custos otimizados pelo algoritmo de fluxo em redes de custo mínimo out-of-kilter, utilizando a simulação tipo contínua do AcquaNet, modelo de rede de fluxo para simulação de bacias hidrográficas. Esse modelo

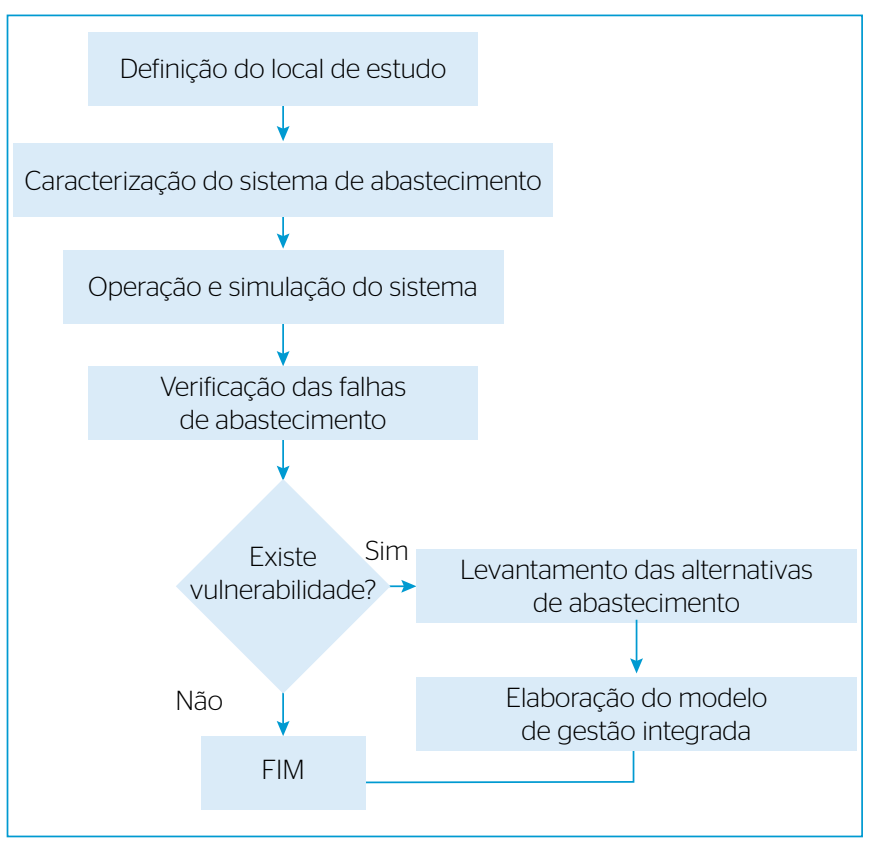

Figura 2 - Fluxograma para definição da metodologia mediante a existência de vulnerabilidade hídrica. requer como dados de entrada: as vazões afluentes aos reservatórios; os volumes iniciais, máximos e mínimos; a curva cota-área-volume; a evaporação do lago; e as demandas hídricas.

As séries de vazões afluentes foram obtidas do relatório de estudos de regionalização para as bacias dos reservatórios do Estado do Ceará, publicado por UFC/COGERH (2013). Nesse relatório, as séries de vazões foram geradas pelo modelo Soil Moisture Accounting Procedure (SMAP) com discretização mensal. Essas vazões compõem uma série para o intervalo entre janeiro de 1912 e dezembro de 2012, que representa o período de análise do estudo.

Para representar a evaporação dos reservatórios, utilizaram-se os dados de evaporação mensal da base de dados das normais climatológicas do Instituto Nacional de Meteorologia (INMET). Esses dados são observados em evaporímetros de Piché com distribuição mensal, sendo escolhidas como representativas as estações meteorológicas mais próximas aos reservatórios: Iguatu, Jaguaruana e Morada Nova. As curvas cota-área-volume foram obtidas da Companhia de Gestão de Recursos Hídricos (COGERH).

A capacidade de acumulação de cada reservatório é imposta no modelo como volume máximo (Tabela 1). O Castanhão possui a maior capacidade de acumulação dentre os reservatórios do Estado do Ceará, com média de $6.650 \mathrm{hm}^{3}$, dos quais $2.200 \mathrm{hm}^{3}$ são reservados para controle de cheias e $4.450 \mathrm{hm}^{3}$ para usos conservativos (urbanos, irrigação, industrial) e não conservativos (piscicultura).

Os volumes mínimos (Tabela 1) representam a parcela do volume total que está estocada abaixo da cota de tomada d'água do reservatório, necessitando de alguma medida estrutural para ser utilizada como oferta hídrica.

Os valores de demanda hídrica foram coletados da COGERH e do Gerenciamento do Risco Climático para a Sustentabilidade Hídrica da Universidade Federal do Ceará, considerando-se as estimativas realizadas para um período sem escassez hídrica.

O sistema Jaguaribe-Metropolitano possui demanda total de $43,19 \mathrm{~m}^{3} / \mathrm{s}$, dos quais $69 \%$ estão concentrados na bacia do Jaguaribe e $31 \%$ na RMF. O açude Gavião, do qual é retirada água para o atendimento de Fortaleza, tem demanda de $10,3 \mathrm{~m}^{3} / \mathrm{s}$, considerado como

Tabela1- Volumes característicos do sistema de abastecimento de Fortaleza. \begin{tabular}{l|l|l} 
Reservatório & Volume máximo $\left(\mathrm{hm}^{3}\right)$ & Volume mínimo $\left(\mathrm{hm}^{3}\right)$
\end{tabular}

\begin{tabular}{l|c|c} 
Aracoiaba & 170,7 & 0,00 \\
\hline Banabuiú & 1.601 & 0,00 \\
\hline Castanhão & 4.451 & 250 \\
\hline Gavião & 32,9 & 16 \\
\hline Orós & 1.940 & 100 \\
\hline Pacajus & 240 & 34 \\
\hline Pacoti-Riachão & 420,00 & 112 \\
\hline
\end{tabular}


o volume demandado pelas ETAs Gavião e Oeste. O Complexo Industrial do Porto do Pecém (CIPP) tem demanda estimada em $1,44 \mathrm{~m}^{3} / \mathrm{s}$ e, juntamente com Fortaleza, forma os grandes usuários da RMF (UFC/COGERH, 2013).

\section{Modelo de gestão integrada de águas urbanas}

Nesta etapa, realizou-se uma pesquisa exploratória com levantamento bibliográfico, obtenção de dados secundários e diálogos com técnicos da Companhia de Água e Esgoto do Ceará (CAGECE). Em seguida, aplicou-se o método indutivo para a elaboração do modelo proposto.

O levantamento bibliográfico foi realizado com o intuito de identificar alternativas de abastecimento para centros urbanos. Os dados secundários foram obtidos da Fundação Cearense de Meteorologia e Recursos Hídricos (FUNCEME) e do IBGE. Esses dados são relacionados com a hidrologia (como o volume precipitado anualmente) e a urbanização do local de estudo (índices de urbanização e número de lotes urbanos).

O método indutivo considera o conhecimento como baseado na experiência do especialista e permite que generalizações sejam derivadas de observações de casos reais e de constatações particulares.

\section{RESULTADOS}

Na simulação do sistema Jaguaribe-Metropolitano, observou-se que o Castanhão, principal reservatório para o abastecimento de Fortaleza, atingiu volume menor que $25 \%$ de sua capacidade máxima em 29,2\% do tempo, implicando no volume mínimo operacional de $220 \mathrm{hm}^{3} \mathrm{em}$ $11 \%$ do período simulado. Com esses níveis, seria necessário um plano de ação para a utilização do volume ainda estocado, com imposição de restrição severa para a utilização desse manancial. As simulações, apresentadas na Figura 3, indicam ainda o esvaziamento completo do Castanhão em $6,52 \%$ dos meses do período simulado.

O reservatório Orós foi inserido no sistema com a finalidade de atender às demandas locais e funcionar como reserva estratégica para o Castanhão. A simulação realizada, no entanto, expôs que ele atende somente às demandas da sua bacia hidrográfica, apresentando falha em 14\% do período simulado (Figura 4).

O Pacoti-Riachão funciona como o principal reservatório de regularização da RMF, e seu comportamento durante o período simulado é exposto na Figura 5. Nessa operação, utilizou-se o gatilho de transferência da região do Jaguaribe para a RMF quando esse reservatório atingiu a metade de sua capacidade máxima de acumulação.

As simulações indicaram ainda que o Pacoti-Riachão atingiu seu volume mínimo operacional em aproximadamente 1,6\% do tempo, impondo déficit de atendimento às demandas de Fortaleza e do CIPP em cerca de 3\% do tempo (Figura 6). A severidade dessa falha é evidenciada pelas vazões máximas de $6 \mathrm{~m}^{3} / \mathrm{s}$ para Fortaleza e $1,44 \mathrm{~m}^{3} / \mathrm{s}$ para o CIPP.

A Figura 7 apresenta o resultado da operação dos sistemas Jaguaribe e Metropolitano de forma agregada, somando as acumulações mensais dos reservatórios pertencentes a cada sistema. Nela, é possível observar os períodos críticos de seca aos quais esses sistemas estão expostos, destacando-se os anos de 1954 a 1963, quando, na simulação, o sistema Jaguaribe enfrentou seu maior período de seca. Essa simulação indica que secas mais prolongadas ou mais intensas, passíveis de ocorrer, levariam ao colapso do sistema.

Verificou-se elevada perda de água por vertimento e por evaporação na bacia metropolitana, ocasionada, em grande parte, pelo excedente de água transferida da região do Jaguaribe. Assim, faz-se necessária a criação de uma política de transferência entre as duas regiões

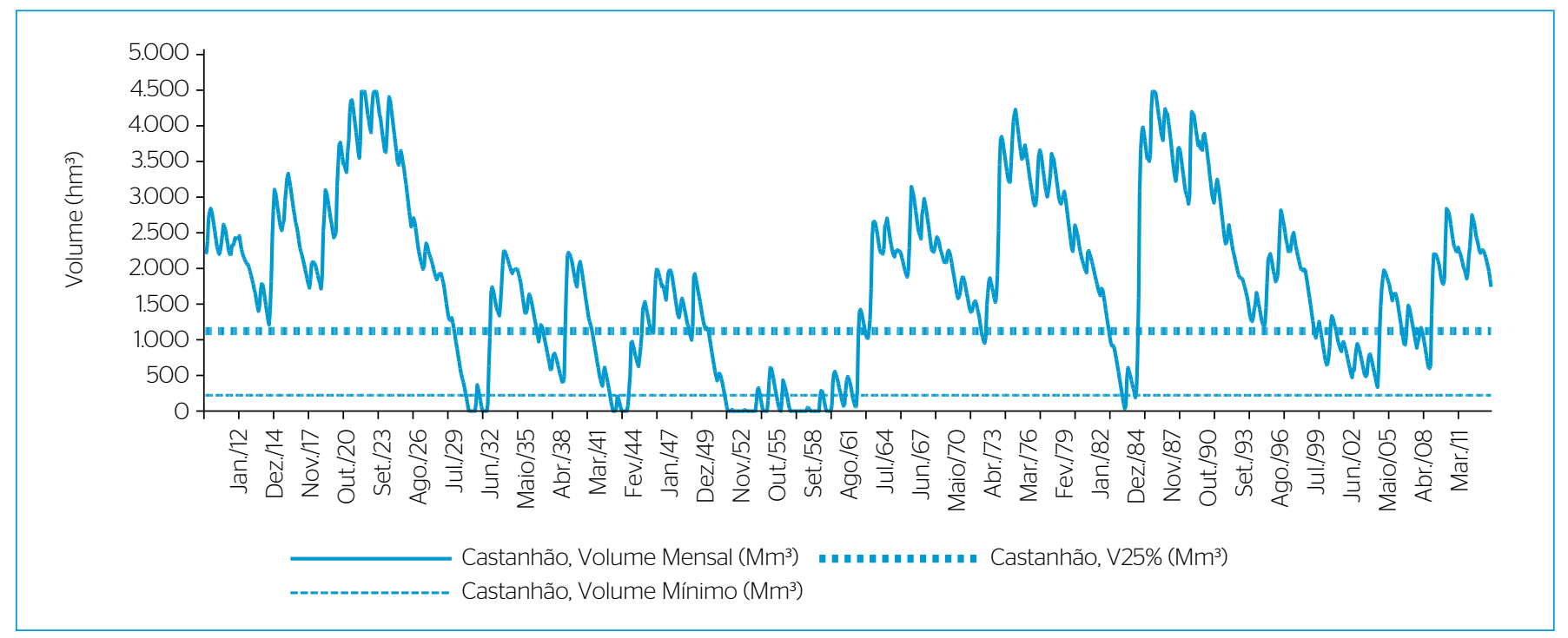

Figura 3 - Comportamento do armazenamento do reservatório Castanhão. 


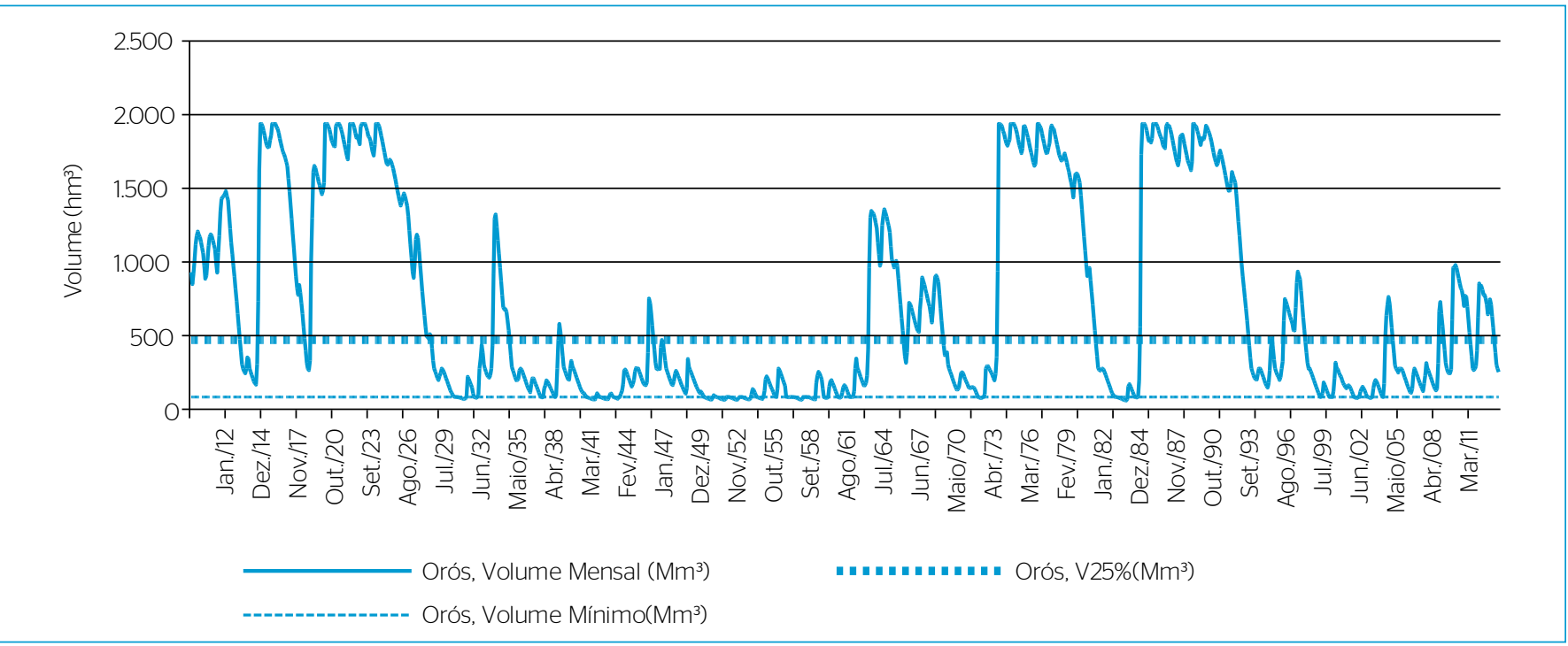

Figura 4 - Comportamento do armazenamento do reservatório Orós.

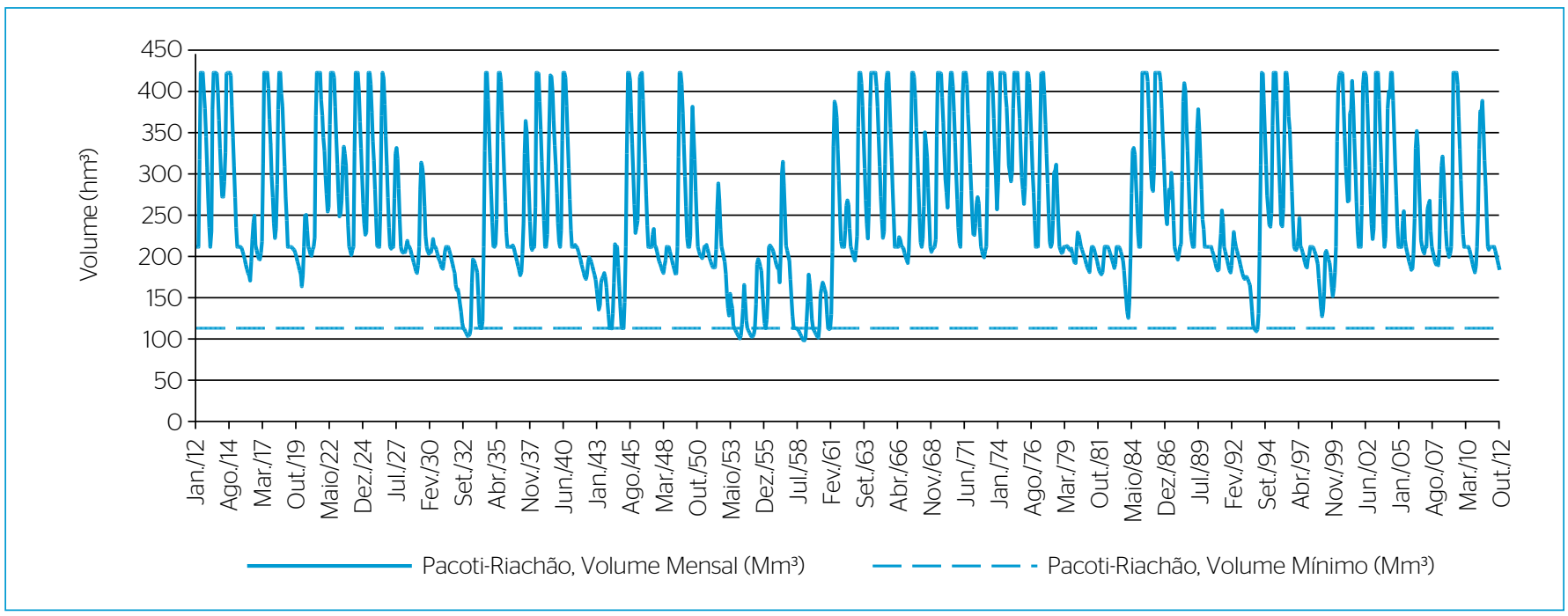

Figura 5 - Comportamento do armazenamento do reservatório Pacoti-Riachão.

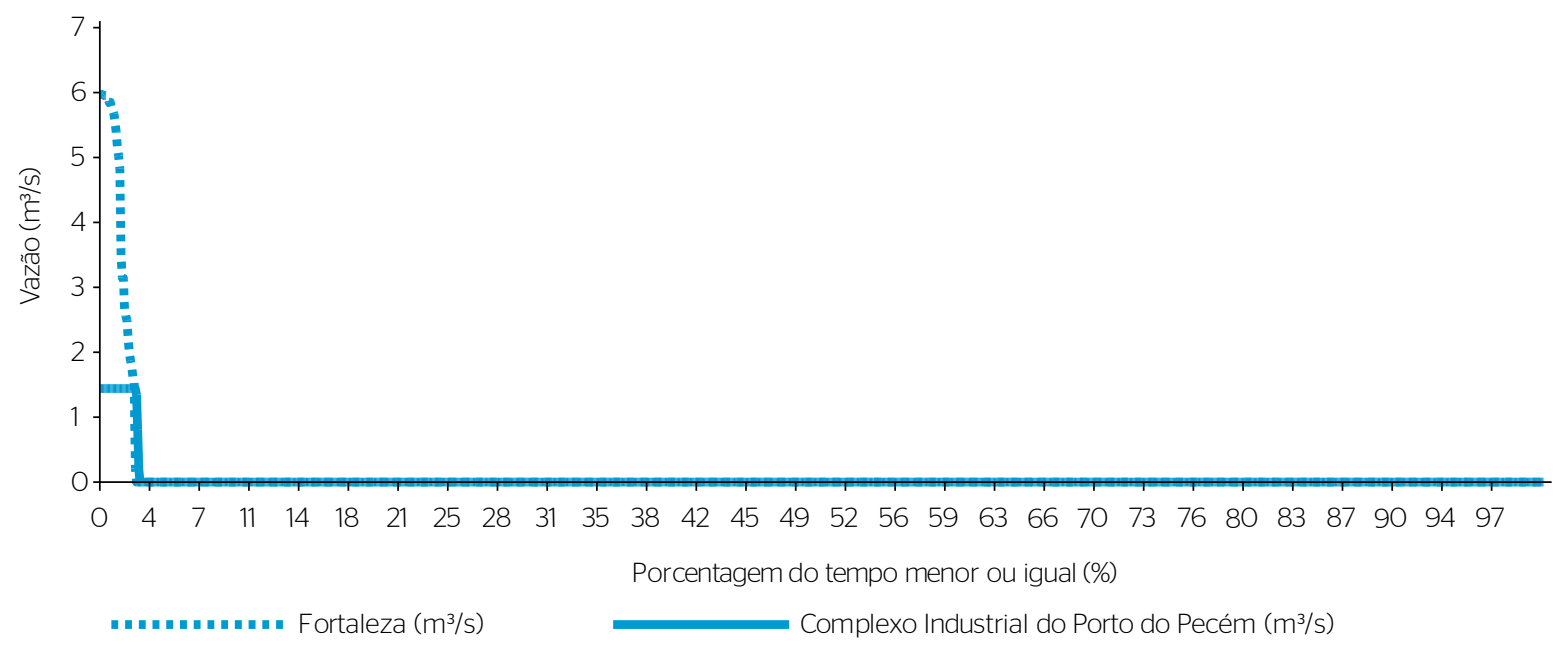

Figura 6 - Curva de permanência dos déficits de atendimento das demandas de Fortaleza e do Complexo Industrial do Porto do Pecém. 
de forma a minimizar as perdas (evaporação e vertimento) e maximizar os benefícios da utilização da água, tornando o sistema eficiente nos múltiplos usos. Essa política pode ser baseada em gatilhos operacionais, que, quando acionados, disparam a ordem de transferência entre as bacias envolvidas.

As falhas da demanda de Fortaleza (Gavião) em 2,56\% do tempo apontam a vulnerabilidade hídrica desse centro urbano (Tabela 2), porém o fator mais preocupante é o esvaziamento dos reservatórios estratégicos nos períodos críticos de seca (décadas de 1930 e 1950), quando apresentaram acumulação abaixo do seu volume morto, chegando a secar. Isso reforça o diagnóstico de que secas mais prolongadas ou mais intensas, passíveis de ocorrer, levariam ao colapso do sistema.

\section{MODELO DE GESTÃO INTEGRADA DAS}

\section{ÁGUAS URBANAS}

As falhas no abastecimento de Fortaleza apresentadas na seção anterior ressaltam a necessidade da utilização de novas fontes de abastecimento e do desenvolvimento de um gerenciamento integrado das águas em meio urbano.

Desse modo, nesta seção é apresentado um modelo conceitual da utilização de novas fontes de abastecimento de água para Fortaleza pautado no contexto da gestão integrada de águas urbanas. Nesse modelo, enfatiza-se o desenvolvimento de estratégias para a gestão da oferta e da demanda de água. A gestão da oferta contempla a utilização e a operação integradas de múltiplos mananciais; a gestão da demanda envolve todas as ações relacionadas aos usos econômicos e sociais da água e à sustentabilidade ambiental.

\section{Gestão da oferta hídrica}

Para a oferta, propõem-se a utilização e a operação integrada de mananciais convencionais (superficial e subterrâneo) e alternativos (reúso, água da chuva e dessalinização). Essa integração pode ser visualizada na Figura 8.

No modelo, o abastecimento da cidade pode ser realizado por quatro meios: águas interestaduais (oriundas da transposição do rio São Francisco); águas inter-regionais (provenientes da bacia do Jaguaribe); águas locais do sistema atual de abastecimento; e águas locais de fontes alternativas (reúso, águas pluviais, águas subterrâneas e dessalinização). Com isso, tem-se um novo sistema de abastecimento, denominado sistema São Francisco-JaguaribeMetropolitano, que funcionaria conforme descrito nos parágrafos a seguir

As águas oriundas do futuro sistema de abastecimento de água bruta (sistema São Francisco-Jaguaribe-Metropolitano) são direcionadas para o açude Gavião, no qual é feita a captação para as ETAs Gavião e Oeste.

Tabela 2 - Frequência de falhas de cada centro de demanda hídrica.

\begin{tabular}{l|c} 
Reservatório & Frequência de falhas (\%) \\
Orós & 13,78 \\
\hline Castanhão & 5,69 \\
\hline Banabuiú & 0,33 \\
\hline Distar & 0,41 \\
\hline Canal do Trabalhador & 5,94 \\
\hline Eixão & 4,87 \\
\hline Aracoiaba & 0 \\
\hline Pacajús & 0 \\
\hline Pacoti-Riachão & 0,74 \\
\hline Gavião & 2,56 \\
\hline CIPP & 2,81 \\
\hline
\end{tabular}

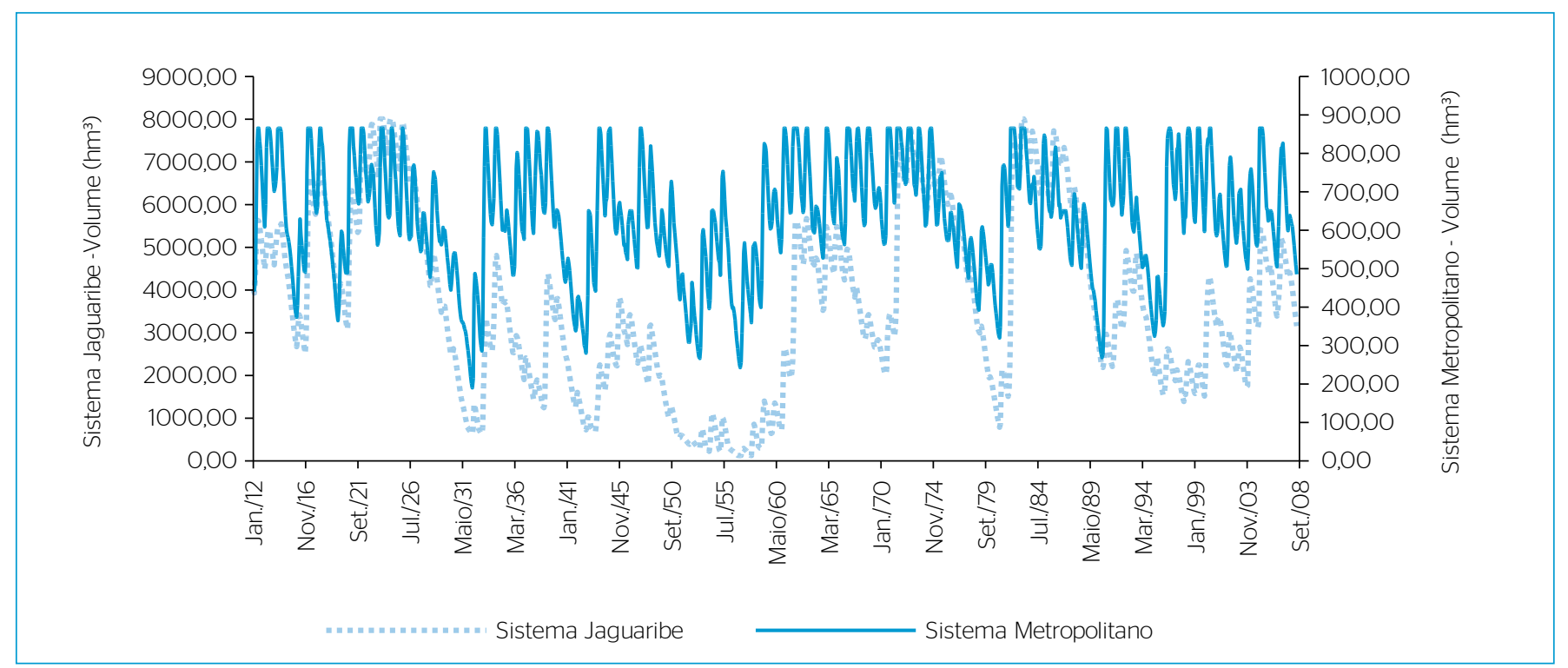

Figura 7 - Acumulação dos sistemas Jaguaribe e Metropolitano para o período de 1912-2012 e demandas atuais. 
Após ser tratada, a água passa por adutoras, estações elevatórias e unidades de reservação para, em seguida, ser distribuída para os lotes urbanos (Figura 8). Das ETAs até a rede de distribuição, podem ocorrer perdas que necessitam ser gerenciadas a fim de aumentar a confiabilidade do abastecimento.
No lote urbano, a água é utilizada e transformada em esgoto doméstico, o qual é direcionado para as Estações de Tratamento de Esgoto (ETEs) ou para o emissário submarino. Nesse modelo, o esgoto passa a ser um recurso aproveitável por meio de três alternativas:

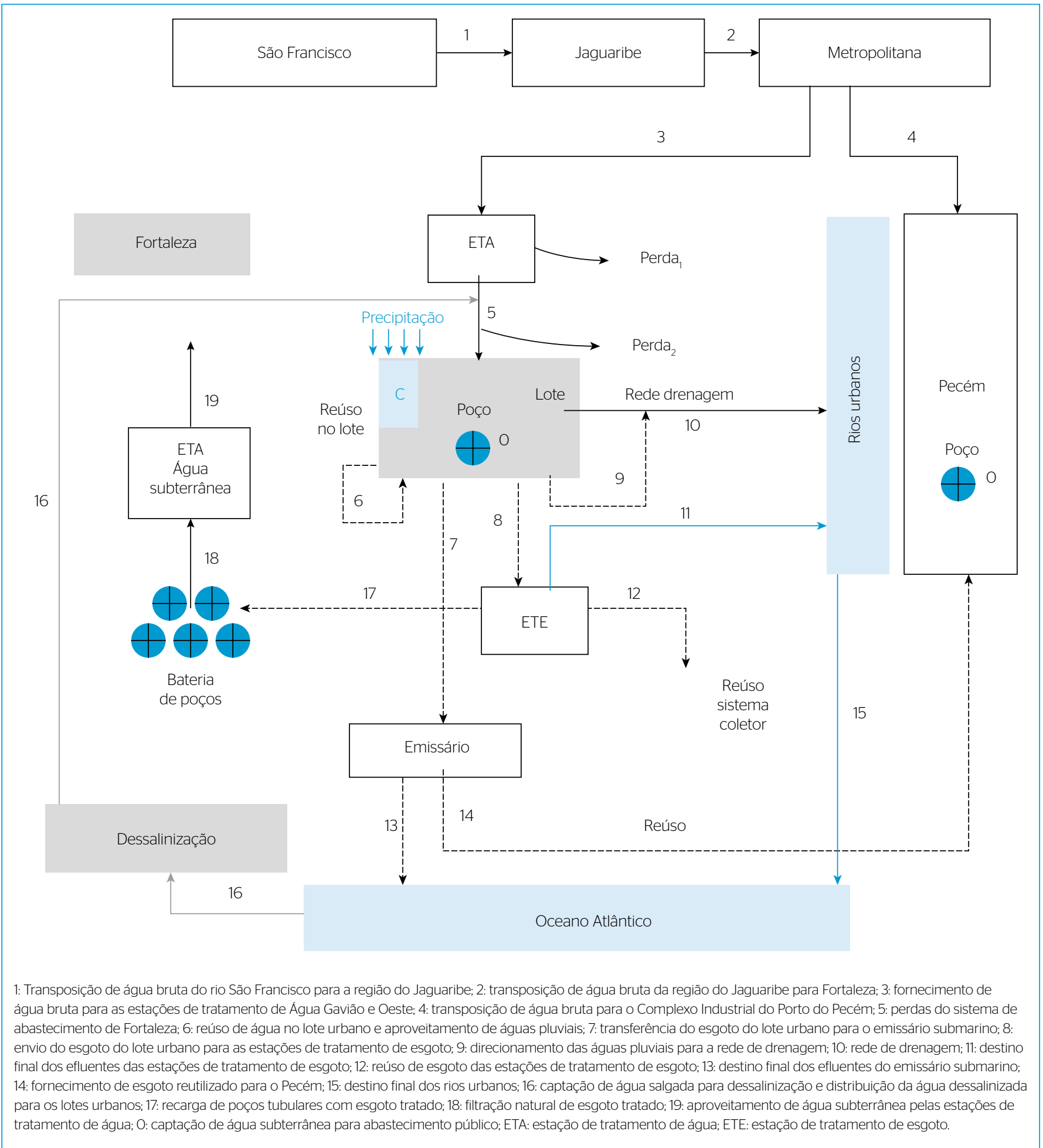

Figura 8 - Modelo de gestão integrada de águas urbanas. 
- reúso de água cinza (água das torneiras, duchas, chuveiros) no lote urbano;

- reúso nas ETEs;

- reúso da parcela do volume de esgotamento direcionado ao emissário submarino de Fortaleza, que foi construído na década de 1970 com a função de transferir para o oceano todo o esgoto coletado da Estação de Pré-Condicionamento de Esgoto.

O reúso de água no contexto da gestão integrada de águas urbanas tem dois papéis: aumentar a oferta hídrica e reduzir o volume de esgoto. Segundo Santos (2003), o reúso já é realizado em algumas companhias do setor de saneamento brasileiro que utilizam água proveniente das ETEs Penha/Companhia Estadual de Águas e Esgotos do Rio de Janeiro (CEDAE) e ABC/Companhia de Saneamento Básico do Estado de São Paulo (SABESP).

Para utilização interna nas edificações, o reúso de água cinza é o mais recomendável, já que essas águas possuem qualidade superior à dos esgotos comuns. As águas cinzas são os efluentes provenientes do uso de chuveiros, lavatórios, bidês, tanques e máquinas de lavar roupas, excluindo-se os esgotos de cozinha e as águas negras, que são os efluentes das descargas dos vasos sanitários.

A reutilização de água cinza tende a contribuir com a redução do consumo de água potável, do volume de contaminantes do solo e do volume de esgoto gerado, apresentando-se como uma alternativa atrativa em termos econômicos e ambientais (BAZZARELLA, 2005).

Nas edificações com reúso, o sistema hidrossanitário é concebido de forma a coletar as águas residuárias segregadas em águas cinzas e águas negras. Assim, essas águas são coletadas por tubulações distintas e conduzidas a tratamentos diferenciados. Esse processo de separação de efluentes por diferentes aparelhos hidrossanitários foi denominado "saneamento ecológico" por Bazzarella (2005).

Outros mananciais aproveitáveis em Fortaleza são as águas pluviais e subterrâneas. Para as águas pluviais, faz-se necessária a implantação de sistemas de captação e utilização nos lotes urbanos e de técnicas estruturais de drenagem compensatória, tais como: bacias de detenção, retenção e infiltração; trincheiras, valas, valetas e pavimentos permeáveis. No caso das águas subterrâneas, propõe-se a sua captação por meio de poços tubulares perfurados no domínio hidrogeológico de dunas/paleodunas.

Ademais, ressalta-se que as águas pluviais têm ocasionado problemas sistemáticos para Fortaleza como inundações, cheias e contaminação de corpos hídricos. Essa cidade possui solo quase totalmente impermeabilizado, impedindo que grande parcela de água da chuva seja absorvida e armazenada no subsolo (PREFEITURA DE FORTALEZA, 2014b). Toda a água da chuva, portanto, escoa superficialmente e se infiltra na rede coletora pelos poços de visita e pelas caixas de ligações domiciliares.
Fortaleza não possui infraestrutura suficiente para o escoamento de água da chuva em galerias apropriadas (PREFEITURA DE FORTALEZA, 2014a). Em períodos chuvosos, as águas pluviais, que deveriam ser drenadas, são lançadas nas redes de esgoto, acarretando sua saturação e o transbordamento do esgotamento sanitário. De maneira contraditória, o esgoto é muitas vezes destinado à rede de drenagem pluvial, ocasionando a contaminação de rios, córregos e águas subterrâneas.

Desse modo, o uso de águas pluviais e o reúso de águas de esgoto propostos no modelo têm seus benefícios tanto para a gestão de secas, constituindo fontes alternativas de abastecimento para uso não potável, quanto para a gestão de cheias urbanas, por meio da redução do volume de esgoto e das águas pluviais.

O reúso do esgoto e o uso das águas pluviais apresentam risco de falha por sua correlação com o total de precipitação, isto é, em anos secos, o volume de água bruta destinado às ETAs é reduzido, ocasionando a diminuição da vazão destinada aos lotes urbanos e, por consequência, da produção de esgoto. Além disso, o volume de água da chuva, que poderia ser aproveitado, também se reduz. Assim, o reúso e a utilização de água da chuva deixam de ser eficazes, revelando a necessidade de um manancial complementar para o abastecimento de Fortaleza. Nesse modelo, propõe-se como fonte complementar a dessalinização da água do mar, o que é possível graças à localização desse município no litoral atlântico.

A dessalinização da água do mar para produção de água potável vem se difundido em vários países, especialmente naqueles com problemas de escassez hídrica. De acordo com Souza (2006), muitos países do Oriente Médio identificaram a dessalinização da água marinha como a solução disponível para o problema da escassez de água.

\section{Gestão da demanda hídrica}

Existem três formas de gerenciar a demanda por água, de acordo com Milutinovic (2006): a primeira, por instrumentos econômicos e financeiros; a segunda, por políticas públicas, como aquelas voltadas à conscientização da população e à restrição do uso; e a terceira, por mudanças tecnológicas, com o desenvolvimento de processos e equipamentos que aumentem a eficiência no uso da água e, com isso, reduzam o consumo.

A tarifa de água é um instrumento poderoso e versátil, capaz de atingir uma série de objetivos, embora possa ocorrer trade-off entre eles. Entre os principais objetivos que podem ser alcançados, citam-se a suficiência de receita das empresas fornecedoras de água, a eficiência econômica, a equidade e a justiça, a redistribuição de renda e a conservação do recurso natural (ANDRÉ, 2012).

A tarifa de água em Fortaleza é de responsabilidade da CAGECE, que foi fundada por meio da Lei no 9.499, de 20 de julho de 1971. Criada como empresa de economia mista, ela é vinculada à Secretaria de Infraestrutura do Ceará e tem no Governo do Estado o seu maior acionário, seguido da Prefeitura de Fortaleza (CAGECE, 2011). 
Como os serviços de coleta de água bruta, tratamento e distribuição de água tratada e de coleta e tratamento de esgoto são regulados, por constituírem um monopólio natural e serem essenciais à saúde, a adoção de uma estrutura tarifária precisa ser aprovada pelos órgãos reguladores do setor. Em Fortaleza, esse órgão é a Autarquia de Regulação, Fiscalização e Controle dos Serviços Públicos de Saneamento Ambiental (ACFOR). Já nos demais municípios do Estado, essa tarefa é de responsabilidade da Agência Reguladora de Serviços Públicos Delegados do Estado do Ceará (ARCE).

Quando se utiliza o mecanismo tarifário para a conservação da água, o parâmetro de maior interesse é a elasticidade-preço da demanda, que mede a variação percentual da demanda em resposta a uma variação no preço da água. Com isso, verifica-se em quanto o consumidor estaria disposto a reduzir seu consumo de água caso ela sofresse aumento no preço.

André (2012) estimou a demanda residencial em Fortaleza considerando efeitos espaciais, isto é, existe uma relação diferente entre preço e consumo de água em cada ponto do espaço. Esse autor relatou ainda que os fatores determinantes para explicar o consumo residencial de água em Fortaleza são o preço médio, a diferença entre o valor total da conta e o valor da conta ao preço marginal, a renda, o número de residentes e o número de cômodos da residência. A elasticidade-preço da demanda foi estimada em 0,61 , em termos absolutos. O autor concluiu também que a variável "diferença" impacta o consumo negativamente e as variáveis "renda", "número de residentes" e "número de cômodos" apresentaram efeito positivo sobre a demanda por água.

A principal medida de gestão da demanda apontada hoje para contribuir com o uso racional da água é a utilização de aparelhos sanitários economizadores. Eles destacam-se na busca pela eficiência do uso da água por reduzir o consumo independentemente da ação do usuário ou de sua disposição em mudar de comportamento. Segundo Alves, Rocha e Gonçalves (2006), aparelhos sanitários correspondem a um conjunto de peças e equipamentos de usos diversos empregados em edifícios, tais como torneiras e válvulas de mictórios. Entre os aparelhos sanitários mais utilizados para promover o uso racional da água, podem-se citar as torneiras economizadoras, os mictórios sem água e com dispositivos de redução de volume e as bacias sanitárias de volume reduzido.

O potencial de economia de água com a instalação dos aparelhos economizadores varia de acordo com as características do uso de água (tempo de uso) e do sistema hidráulico predial (vazão dos equipamentos hidrossanitários). Gonçalves (2007) e SABESP (2012) relataram o maior potencial de economia de água em torneiras de lavatórios com sensor de presença $(87,5 \%)$ e arejador em sistema com pressão entre 150 e $200 \mathrm{kPa}(76,0 \%)$, respectivamente. Esses dois estudos estimam economia de água de $50 \%$ em torneiras com o uso de arejadores, sendo que, para essa economia, a SABESP (2012) define pressão máxima de
$60 \mathrm{kPa}$. Normalmente, encontram-se pressões inferiores a $60 \mathrm{kPa}$ em sistemas hidráulicos prediais de habitações de interesse social térreas.

Os estudos realizados por SECOVI (2005) relatam os menores potenciais de economia, de 24,0 e 22,5\%, para torneiras com arejadores.

A conscientização dos cidadãos e sua mudança de hábitos e comportamentos, por meio de pequenas remodelações possíveis de efetuar em casa, constituirão um benefício para todas as formas de vida que dependem da água e contribuirão para a maior e melhor racionalização desse recurso. Assim, propõe-se o desenvolvimento de políticas que promovam a troca ou instalação desse tipo de aparelho nos lotes urbanos e propiciem incentivos para empresas de inovação tecnológica nesse setor.

\section{Contribuição volumétrica dos novos mananciais}

Com base no levantamento da série histórica de precipitações de Fortaleza, bem como no conhecimento do sistema de esgotamento sanitário da região e da área do município, foram levantadas hipóteses sobre a contribuição volumétrica dos novos mananciais para o abastecimento da cidade.

O sistema de esgotamento sanitário de Fortaleza atende, atualmente, $61 \%$ da população, com $49,1 \%$ da cobertura pelo sistema de macrocoleta (emissário submarino) e 11,9\% pelos sistemas isolados (PREFEITURA DE FORTALEZA, 2014a).

Como parâmetros, consideraram-se o consumo per capita de Fortaleza de $200 \mathrm{~L} /$ hab./dia e a prática de reúso dentro do próprio lote por $10 \%$ da população. Desse percentual, $30 \%$ do esgoto produzido será reutilizado. Do esgoto produzido pelo emissário submarino e pelas ETEs isoladas, considerou-se que 60 e 10\%, respectivamente, serão reutilizados como fontes alternativas. Assim, as águas de reúso seriam responsáveis por $25,54 \%$ do suprimento de água de Fortaleza, com $23,14 \%$ desse total produzido pela vertente marítima, $1,46 \%$ por reaproveitamento no próprio lote e $0,93 \%$ pelas ETAs isoladas.

O município de Fortaleza apresenta área de $314,9 \mathrm{~km}^{2}$ (IPLANFOR/ FCPC, 2015). Desse total, de acordo com a IPLANFOR/FCPC (2015), $38 \%$ correspondem à área urbana edificada, com taxa média de ocupação de $50 \%$ do lote.

Supondo que $10 \%$ da população reutilizará água de chuva e admitindo coeficiente de aproveitamento no lote de 0,8 (ou seja, $80 \%$ do que precipita é aproveitado), será obtido aproveitamento de 1,97\% de toda a água que precipita. Assim, considerando que a precipitação média anual é de $1.300 \mathrm{~mm}$, a vazão de água disponível para os usos seria, em média, de $200 \mathrm{~L} / \mathrm{s}$.

A contribuição da água dessalinizada foi fixada em $2 \mathrm{~m}^{3} / \mathrm{s}$, funcionando durante todo o tempo. Essa consideração visa observar o impacto da contribuição dessa fonte alternativa em todo o sistema de abastecimento. Em períodos úmidos, a utilização dessa água seria inviável, haja vista a disponibilidade de água bruta nos reservatórios 
locais e os custos de produção relacionados a essa fonte alternativa. Assim, uma opção seria a utilização de água dessalinizada somente em momentos de seca severa ou extrema, quando a planta funcionaria com capacidade plena de $2 \mathrm{~m}^{3} / \mathrm{s}$, atendendo em torno de $20 \%$ da demanda total de Fortaleza.

\section{CONCLUSÃO}

O artigo discutiu a gestão integrada de águas urbanas como estratégia para a redução da vulnerabilidade hídrica.

A análise da vulnerabilidade apontou falhas em 2,56\% do tempo para o local de estudo, além de elevadas perdas de água por vertimento e evaporação. Esse diagnóstico atestou a dependência da cidade de Fortaleza das águas da bacia do Jaguaribe.

Para a preparação às secas, foi apresentado um modelo de gestão integrada de águas urbanas com foco na oferta e na demanda hídricas. Nesse modelo, o abastecimento ocorre tanto por fontes tradicionais (águas armazenadas em reservatórios) como por mananciais alternativos (águas subterrâneas, águas pluviais e dessalinização de água do mar), tendo sido inserido também o esgoto com recurso aproveitável. Propôs-se ainda a redução de perdas, a utilização de aparelhos sanitários economizadores e o uso de mecanismos financeiros como medidas de gestão da demanda hídrica.

O modelo apresentado opera a transição da tradicional gestão de águas, fragmentada em seus componentes (abastecimento, esgotamento $\mathrm{e}$ manejo de águas pluviais) - em muitos casos já fracassados em lidar com as pressões existentes - , para uma gestão integradora, que possibilita a flexibilização dos sistemas hídricos por meio de diversas fontes de oferta de água. A abordagem também se insere como medida de gestão de conflitos.

Ressalta-se que, para a implementação de um modelo integrado de gestão das águas urbanas, faz-se necessária a integração das políticas de recursos hídricos, ambientais e de planejamento do uso do solo.

\section{AGRADECIMENTOS}

Os autores agradecem ao Conselho Nacional de Desenvolvimento Científico e Tecnológico ( $\mathrm{CNPq}$ ) pelo apoio financeiro concedido ao desenvolvimento da pesquisa.

\section{REFERÊNCIAS}

ALVES, W.C.; ROCHA, A.L:; GONÇALVES, R.F.(2006) Aparelhos Sanitários Economizadores. In: GONÇALVES, R. F. (coord.). Uso Racional da Água em Edificações. Rio de Janeiro: ABES, Projeto PROSAB. 352 p.

ANDRÉ, D. de M. (2012) Determinantes espaciais e econômicos da demanda residencial por água em Fortaleza, Ceará. 2012. 74f. Dissertação (Mestrado em Economia) - Universidade Federal do Ceará, Fortaleza.

BAZZARELLA, B.B. (2005) Caracterização e aproveitamento de água cinza para uso não potável em edificações. 165f. Dissertação (Mestrado em Engenharia Ambiental) - Universidade Federal do Espírito Santo, Vitória.

COMPANHIA DE ÁGUA E ESGOTO DO CEARÁ (CAGECE). (2O11) História. Fortaleza: CAGECE. Disponível em: <https://www.cagece. com.br/quem-somos/historia/>. Acesso em: 2 nov. 2017.

COMPANHIA DE SANEAMENTO BÁSICO DO ESTADO DE SÃO PAULO (SABESP). (2012) Equipamentos Economizadores. São Paulo: Companhia de Saneamento Básico do Estado de São Paulo. Disponível em: <http://site.sabesp.com.br/site/interna/Default. aspx?secaold=145>. Acesso em: fev. 2016.

GONÇALVES, O.M. (2007) Manual de Conservação de Água. Programa de Conservação de Águas. São Paulo: Gênesis Takaoka. 107 p.
INSTITUTO BRASILEIRO DE GEOGRAFIA E ESTATÍSTICA (IBGE). (2012) Censo Demográfico 2010. Brasil: Instituto Brasileiro de Geografia e Estatística.

INSTITUTO DE PESQUISA E ESTRATÉGIA ECONÔMICA DO CEARÁ (IPECE). (2014) Perfil básico municipal 2014 - Fortaleza. Ceará: Secretária do Planejamento e Gestão/Instituto de Pesquisa e Estratégia Econômica do Ceará.

INSTITUTO DE PLANEJAMENTO DE FORTALEZA (IPLANFOR)/ FUNDAÇÃO CEARENSE DE PESQUISA E CULTURA (FCPC). (2O15) Interpretação da forma de Fortaleza: Urbanismo e Mobilidade. In: INSTITUTO DE PLANEJAMENTO DE FORTALEZA (IPLANFOR)/ FUNDAÇÃO CEARENSE DE PESQUISA E CULTURA (FCPC). Plano Mestre Urbanístico e de Mobilidade - Fortaleza 2040. Relatório Preliminar. Fortaleza: IPLANFOR/FCPC.

LABORATÓRIO DE SISTEMA DE SUPORTE À DECISÃO (LABSID). Modelo de Rede de Fluxo - Acquanet. (2002) São Paulo: Universidade de São Paulo/Laboratório de Sistema de Suporte à Decisão

MILUTINOVIC, M. (2006) Literature review of water demand. 2006 32Of. Doutorado (Tese em Engenharia Civil e Ambiental) - Instituto de Tecnologia de Massachusetts, Massachusetts. 
ORGANISATION FOR ECONOMIC CO-OPERATION AND DEVELOPMENT (OECD). (2016) Water Governance in Cities. Paris: Organisation for Economic Co-operation and Development. 142 p.

ORGANIZAÇÃO DAS NAÇÕES UNIDAS PARA A ÁGUA (UN-WATER). (2013) Un-Water Analytical Brief on Water security and the Global Water Agenda. Canadá: Institute for Water, Environment \& Health (UNU-INWEH). $47 \mathrm{p}$.

PHILIP, R.; ANTON, B.; STEEN, V.D. (2O11) Kit de Treinamento SWITCH: Gestão Integrada das Águas na Cidade do Futuro. Alemanha: ICLEI European Secreteriat GmbH. Módulo 1: Planejamento Estratégico Preparando-se para o Futuro. 53 p.

PHILIP, R.; SALIAN, P. (2011) Kit de Treinamento SWITCH: Gestão Integrada das Águas na Cidade do Futuro. Alemanha: ICLEl European Secreteriat $\mathrm{GmbH}$. Módulo 6: Auxílio à Decisão Escolhendo um Caminho Sustentável. 49 p.

PREFEITURA DE FORTALEZA. (2014a) Diagnóstico do Sistema de Esgotamento Sanitário. Convênio de Cooperação Técnica entre Companhia de Água e Esgoto do Ceará (CAGECE) e Agência Reguladora de Fortaleza (ACFOR). Fortaleza: Secretaria Municipal de Urbanismo e Meio Ambiente. 80 p.
. (2014b) Plano Municipal de Saneamento Básico de Fortaleza. Convênio de Cooperação Técnica entre Companhia de Água e Esgoto do Ceará (CAGECE) e Agência Reguladora de Fortaleza (ACFOR). Fortaleza: Secretaria Municipal de Urbanismo e Meio Ambiente. 280p.

SANTOS, G.J. (2003) Sistema de reúso de água: projetos e estudos de casos. In: MANCUSO, P.C.S.; SANTOS, H.F. Reúso de Água. São Paulo: Manole. p. 501-511.

SINDICATO DOS EMPREGADOS EM EMPRESAS DE COMPRA, VENDA, LOCAÇÃO E ADMINISTRAÇÃO DE IMÓVEIS RESIDENCIAIS E COMERCIAIS DE SÃO PAULO (SECOVI). (2005) Manual do Uso Racional da Água. São Paulo: Secovi. 25 p.

SOUZA. L.F. (2006) Dessalinização como fonte alternativa de água potável. Norte Científico, v. 1, n. 1.

UNIVERSIDADE FEDERAL DO CEARÁ (UFC)/COMPANHIA DE GESTÃO DE RECURSOS HIIDRICOS (COGERH). (2013) Relatório dos Estudos de regionalização de parâmetros de modelo hidrológico chuva-vazão, para as bacias totais e incrementais dos reservatórios monitorados pela Companhia de Gestão dos Recursos Hidricos. Convênio UFC/COGERH/FCPC. Fortaleza: UFC/COGERH. 24 p.

DOI: 10.1590/S1413-41522019181776ERRATUM

\title{
Errata
}

No artigo "Proposta de gestão integrada das águas urbanas como estratégia de promoção da segurança hídrica: o caso de Fortaleza", DOI: 10.1590/S1413-41522019181776, publicado no periódico Eng. Sanit. Ambient. [online]. 2019, vol.24, n.2, p.239-250, na página 239.

\author{
Onde se lia: \\ Louisse Caroline Peixoto Xavier
}

\section{Leia-se:}

Louise Caroline Peixoto Xavier 